Bryn Mawr College

Scholarship, Research, and Creative Work at Bryn Mawr College

Graduate School of Social Work and Social

Graduate School of Social Work and Social

Research Faculty Research and Scholarship

Research

2004

\title{
Termination of Supplemental Security Income Benefits for Drug Addiction and Alcoholism: Results of a Longitudinal Study of the Effects on Former Beneficiaries
}

James A. Swartz

Jim Baumohl

Bryn Mawr College, jbaumohl@brynmawr.edu

Arthur J. Lurigio

Let us know how access to this document benefits you.

Follow this and additional works at: http://repository.brynmawr.edu/gsswsr_pubs

Part of the Social Work Commons

\section{Custom Citation}

Swartz, James A., Jim Baumohl, and Arthur J. Lurigio. "Termination of Supplemental Security Income Benefits for Drug Addiction and Alcoholism: Results of a Longitudinal Study of the Effects on Former Beneficiaries." Social Service Review 78 (2004): 96-124.

This paper is posted at Scholarship, Research, and Creative Work at Bryn Mawr College. http://repository.brynmawr.edu/gsswsr_pubs/20

For more information, please contact repository@brynmawr.edu. 


\title{
Termination of Supplemental Security Income Benefits for Drug Addiction and Alcoholism: Results of a Longitudinal Study of the Effects on Former Beneficiaries
}

James A. Swartz

University of Illinois at Chicago

Jim Baumohl

Bryn Mawr College

Arthur J. Lurigio

Loyola University

\begin{abstract}
This article reviews the results of a multisite cohort study on effects of terminating Supplemental Security Income benefits for drug addiction and alcoholism. Within 2 years of the program's termination, 35-43 percent of participants requalified for disability benefits for another impairment. Regardless of requalification status, substance abuse treatment participation declined sharply and illegal drug use was prevalent. Although many of those who did not requalify lost income, medical benefits, and housing, these losses lessened over time and were not associated with increased psychological or medical problems or with declines in other aspects of participants' lives.
\end{abstract}

Social Service Review (March 2004).

(C) 2004 by The University of Chicago. All rights reserved.

0037-7961/2004/7801-0006\$10.00 
Supplemental Security Income (SSI) for drug addiction and alcoholism (DA\&A) began in 1974 as a small federal program of a few thousand individuals disabled for work. Recipients tended to suffer mainly from alcoholism-related impairments, such as cirrhosis of the liver. But the DA\&A program was beset by interrelated administrative, legal, and political difficulties: a well-documented problem in predicting and controlling caseload size, a perceived failure to control the behavior of its beneficiaries (notably, their drinking and illegal drug use) and thus avoid scandal, and a historic failure to return some significant number of recipients to work (Hunt and Baumohl 2003a). These difficulties eventually culminated in the legislative termination of the program in March 1996.

As late as the mid-1980s, the SSI DA\&A program had fewer than 10,000 beneficiaries. This number doubled by 1990 and approached 80,000 by the end of 1993. By June 1996 there were almost 170,000 SSI DA\&A recipients. Several factors contributed to this astonishing growth. Because a work disability due to drug addiction or alcoholism is difficult to substantiate, the program was an easy target for case advocates and attorneys specializing in public benefits. A series of federal court rulings liberalized eligibility rules, and persistent claimants were rewarded by a very high reversal rate of denials on appeal. Some of this legal onslaught was supported by various states (e.g., Illinois), which worked aggressively to shift state-supported general assistance recipients to the federally funded SSI program, thereby lessening the state's financial burden. Moreover, as part of the political backlash against the wholesale disqualification of SSI disability recipients during the first Reagan administration, Congress created new rules for SSI disability reviews. These rules effectively stalled the decertification of those whose conditions had improved sufficiently to disqualify them for benefits.

The growth of the DA\&A program also entailed a qualitative transformation. Although the program was populated initially by aging alcoholics, almost half of all DA\&A beneficiaries were classified as illegal drug abusers by the Social Security Administration (SSA) in the years just prior to the program's end. ${ }^{1}$ This brought intensely negative congressional and media attention (Hunt 2000). Increasingly, the program was portrayed as a wasteful entitlement that facilitated addiction by disbursing monthly checks to drug addicts (e.g., Satel and Glazer 1993; Cohen 1994; Satel 1995).

The negative perception was supported by only very modest empirical evidence (e.g., Shaner et al. 1995), but the program was highly vulnerable on this issue. The enabling legislation for SSI (U.S. PL 92-603) required that DA\&A recipients participate in substance abuse treatment and allow their benefit checks to be managed by an individual or institutional representative payee, such as a caseworker, mental health 
professional, or treatment facility. However, the SSA had no money to pay for treatment or to train and supervise representative payees. As a result, the treatment mandate was poorly and inconsistently enforced until Congress reformed the DA\&A program in 1994 (U.S. PL 103-296). At this time, the SSA was directed to fund a greatly expanded number of referral and monitoring agencies (RMAs), which would act as statebased SSA proxies, arranging substance abuse treatment and vigorously monitoring compliance with the treatment mandate. The SSA was also instructed to emphasize the use of institutional representative payees, who would presumably be tougher and more disciplined than family members and friends (but see Hunt and Baumohl 2003b). The legislation limited lifetime benefits to 3 years, making caseload size and program costs far more predictable. As with other SSI disability categories, the DA\&A classification had previously entailed no time limits.

In March 1996, before the effects of the 1994 legislative changes could be assessed, Congress acted to abolish the DA\&A program, effective January 1997 (U.S. PL 104-121, sec. 105). Those affected by the discontinuation of the DA\&A classification lost about $\$ 500$ in monthly cash benefits (a little more in states like California that supplemented the federal assistance). Many also lost Medicaid benefits, because most states tie Medicaid eligibility to federal disability benefits: those who failed to requalify for disability benefits under another impairment category or who could not qualify for another Medicaid-enabling form of government assistance, such as Temporary Assistance for Needy Families (TANF), found themselves no longer covered by Medicaid. But no one could accurately predict the long- or short-term consequences of these changes. Indeed, no one, including the SSA, knew much about DA\&A recipients beyond basic information, such as demographics, employment history, incomes, and impairment categories. Though a General Accounting Office study reported widespread use of cash benefits by DA\&A recipients to support alcohol and drug habits (see Cohen 1994), corroborating evidence consisted entirely of anecdotal statements by program administrators and officials; there were no empirically sound or direct assessments of alcohol and illegal drug use by DA\&A recipients. Sensationalistic press accounts and anecdotal reports aside, little was known about actual levels of alcohol and illegal drug use by DA\&A recipients (Pollack et al. 2002). It was also unclear how many SSI DA\&A recipients would be able or willing to work. In short, the unprecedented elimination of an impairment category in a disability program, along with the lack of reliable information about the affected population, left open to conjecture the answers to important questions about the repercussions of the 1996 legislation.

In the fall of 1996, just before the scheduled end of the DA\&A program, a representative from the federal Center for Substance Abuse Treatment (CSAT) convened a group of independent researchers from 
various institutions across the country. The event was organized to discuss collaboration on a study that would examine the effects of the DA\&A program's termination. The initial meeting led to a 2-year, multisite, longitudinal cohort study of SSI DA\&A recipients. ${ }^{2}$ The DA\&A multisite study, as it came to be called, sought first to determine how many former DA\&A recipients would requalify for SSI benefits under a different impairment category (e.g., for psychiatric or medical problems) and then to assess the effects of the loss of disability benefits on those who did not requalify.

This study concluded data collection in the summer of 1999. Its main findings have been published recently as a series of articles, with each article exploring different effects of lost DA\&A benefits (e.g., Campbell, Baumohl, and Hunt 2003; Guydish et al. 2003; Norris et al. 2003; Speiglman et al. 2003; Swartz and Martinovich 2003a, 2003b). A number of articles based on subsets of the full sample or closely related samples have also appeared in peer-reviewed journals (e.g., Goldstein et al. 2000; Swartz, Lurigio, and Goldstein 2000; Watkins, Podus, and Lombardi 2001; Anderson et al. 2002; Swartz, Hsieh, and Baumohl 2003).

The present article summarizes the findings of this multisite study and briefly considers the policy implications of these results. The main hypothesis of the multisite study was that those who did not requalify for disability benefits and who did not replace their lost income would fare the most poorly in virtually all assessed areas of functioning. The outcomes for nonrequalifying participants would be in comparison to the outcomes of those who requalified for benefits or who legally replaced their lost income.

Accordingly, this review of the study's findings is organized around the following six research questions, which address the primary functional areas assessed. First, how did the loss of DA\&A benefits affect income levels, and what proportion of those who did not requalify replaced their lost income through legal means, such as employment or income assistance under another state or federal program (e.g., TANF)? Second, would those who failed to requalify experience increases in homelessness and hunger (i.e., would they experience greater material hardships) as compared to those who did requalify for disability benefits or to those who replaced this lost income through other income assistance or employment? Third, did the loss of medical benefits under Medicaid lead to decreased access to health care for those failing to requalify and, consequently, relate to more reported psychiatric and medical problems, as well as to increases in the use of emergency rooms for medical services? Fourth, all DA\&A recipients (regardless of requalification status) were no longer required to participate in substance abuse treatment as a result of the congressional decision to terminate the DA\&A program: what effect did this revocation of the treatment mandate have on rates of treatment participation? Fifth, how prevalent 
was the use of alcohol and illegal drugs by former DA\&A recipients, and were the rates of use affected by income management through representative payees or by receipt of federal cash benefits? Sixth, and finally, in terms of increased discord with family and friends, increased criminal behavior, added psychological symptoms, or increased medical problems, did losing DA\&A benefits result in deterioration in quality of life among those who did not requalify and did not replace their lost disability income?

\section{Method}

Nine sites participated in the DA\&A study: five in California (San Francisco, Oakland, Stockton, San Jose, and Los Angeles), two in the Midwest (Chicago and Detroit), and two in the Northwest (Portland and Seattle). ${ }^{3}$ In aggregate, the DA\&A population for the nine sites represented 26 percent of the national DA\&A population as of March 1, 1996 (Wittenburg et al. 2003). However, as the concentration of these West Coast sites suggests, they were not selected randomly to represent the national population. Instead, they constituted a convenience sample. They were selected by virtue of their existing funding sources: the Robert Wood Johnson Foundation sponsored studies (in Chicago and Northern California) of the policy implications of eliminating the SSI DA\&A program; CSAT included sites that were part of its Target Cities initiative. This initiative was launched to study the effects of centralizing the assessment and referral of substance abusers seeking admission to publicly funded treatment programs (see Guydish and Claus 2002). By incorporating these existing research infrastructures, CSAT sought to enable a broader study of the effects of terminating the SSI DA\&A program.

The study was not centrally administered by CSAT and did not have a single principal investigator. It was managed instead as a collaboration in which all of the sites participated, with decisions about methodology reached by consensus and arbitrated by a CSAT project officer (Swartz, Tonkin, and Baumohl 2003). Priority was given to standardizing study eligibility criteria and to developing a mandatory set of core interview questions, as well as to the timing of the baseline and follow-up interviews. Beyond these common protocol elements, sites could adapt the implementation of the study to local environments, budgets, and research infrastructures. Sites were also permitted to address additional research questions through addenda to the core instrument. This flexibility resulted in variation among the sites with respect to recruitment protocols, interview locations, and informed-consent procedures. The decision to collect and test urine samples was another variation. Although any one of these differences might have lessened the comparability of samples across sites, the extent to which results are affected could not be assessed. The differences were not systematic, and the 
Table 1

Baseline Sample Sizes and Protocol Variations by Site

\begin{tabular}{|c|c|c|c|c|c|}
\hline Site & $\begin{array}{l}\text { Baseline } \\
\text { Sample } \\
\text { Size }(N)^{\mathrm{a}}\end{array}$ & $\begin{array}{l}\text { Sampling } \\
\text { Frame }^{\mathrm{b}}\end{array}$ & $\begin{array}{l}\text { Recruitment } \\
\text { Rate }(\%)\end{array}$ & $\begin{array}{c}\text { Completed } \\
\text { Three } \\
\text { or More } \\
\text { Follow-Up } \\
\text { Interviews (\%) }\end{array}$ & $\begin{array}{c}\text { Urine } \\
\text { Specimen } \\
\text { Collected }^{\mathrm{c}}\end{array}$ \\
\hline Chicago & 255 & SSA & 56 & 86 & $\mathrm{X}$ \\
\hline Detroit & 201 & RMA & 71 & 92 & \\
\hline Seattle & 321 & RMA & 73 & 90 & $\mathrm{X}$ \\
\hline Portland & 182 & RMA & 72 & 93 & $\mathrm{X}$ \\
\hline Oakland & 146 & RMA & 67 & 97 & \\
\hline San Jose & 66 & RMA & 67 & 92 & \\
\hline Stockton & 154 & RMA & 68 & 96 & \\
\hline San Francisco & 153 & RMA & 68 & 88 & \\
\hline Los Angeles & 286 & SSA & 73 & 100 & $\mathrm{X}$ \\
\hline
\end{tabular}

Source. - Swartz, Tonkin, and Baumohl 2003, pp. 77-122. Copyright 2003 by Federal Legal Publications, Inc. Reprinted and adapted with permission.

NoTE.-All figures shown are based on unweighted data.

a Total baseline sample size is 1,764 and includes all participants with completed baseline interviews. This sample excludes those who completed a baseline interview and who were later identified as being recipients of concurrent SSI and SSDI benefits.

${ }^{b}$ SSA indicates that the site derived their sampling frame from a list provided by the Social Security Administration that completely enumerated the local population. RMA indicates that the site used data from the local Referral and Monitoring Agency. The RMAderived lists excluded individuals who did not comply with or had completed the DA\&A program drug treatment mandate. The RMA lists were therefore incomplete and potentially biased representations of the DA\&A population receiving disability benefits in that locale.

${ }^{c}$ An $\mathrm{X}$ indicates that urine specimens were collected at the 12-, 18-, and 24-month follow-up interviews. The sites in Chicago, Los Angeles, and Seattle attempted to collect urine specimens from all participants at these three interviews. The Portland site collected urine specimens from only about half of its participants at each of these three follow-up interviews. These specimens were collected as part of a study to test the effects of collecting urine specimens on the levels of self-reported use for the tested drugs.

populations at each site were demographically very different. Site differences in sampling frames, sampling fractions, and recruitment rates were more systematic than the differences in recruitment protocols, interview locations, and informed-consent procedures. So too, these sampling and recruitment rate differences were more important in their effects on the representativeness of the samples with respect to their local populations and with respect to the aggregate multisite population. We address these issues in more detail below (see table 1).

\section{Participants}

The baseline sample consisted of 1,764 former SSI DA\&A recipients. Participants eligible for the study were between the ages of 21 and 59, received SSI DA\&A benefits in 1996, did not concurrently receive DI benefits, and did not reside in a prison, jail, hospital, or other institu- 
tional setting at the time of the baseline interview. The study focused on those who received SSI only, because compared to DI recipients, SSI recipients had more limited work histories and the fewest material resources. It seemed likely that those who received SSI only would be the most adversely affected by the discontinuation of cash benefits and Medicaid coverage. Despite the SSI-only eligibility requirement, some sites unintentionally recruited and interviewed beneficiaries in their baseline samples who received SSI and DI concurrently. The data from these participants were subsequently excluded from the aggregate database.

Demographic information collected at baseline for the full study sample is shown in table 2, disaggregated by study site. Summarizing across sites, the average DA\&A recipient was male (62 percent), African American (50 percent), and 43 years old ( $\mathrm{SD}=7.9$ years). The average recipient possessed less than a high school education ( mean $=10.7$ years, $\mathrm{SD}=2.3$ years), was never married or divorced or separated (87 percent), and was not in drug treatment for at least 1 month in the 6 months prior to baseline (63 percent). The average DA\&A recipient reported two or more medical problems (79 percent) or psychiatric problems (72 percent) in the 6 months prior to the survey. Between 3 and 4 percent of the study participants also reported HIV infection, a much higher rate than that for the U.S. general population (Centers for Disease Control and Prevention 2001). In terms of their self-reported use of alcohol or drugs, 16 percent reported daily or more frequent use of alcohol, and 9 percent reported daily or more frequent use of cocaine or heroin. Finally, over one-fourth of the participants, 27 percent, reported committing a crime in the 6 months prior to the baseline survey. This relatively high self-reported rate of criminal activity is consistent with rates derived from arrest histories. Studies indicate that between 75 and 90 percent of SSI DA\&A recipients had a record of at least one arrest (Davies, Iams, and Rupp 2000; Swartz and Lurigio, in press).

Given the considerable demographic variation among the sites, these statistical averages must be interpreted cautiously. Every measure shown in table 2 yielded a statistically significant site difference. In part, this variation reflects differences in general population demographics among the sites. In Portland, for example, census data from the year 2000 indicate that the general population is 78 percent white and only 6 percent African American, whereas in Chicago, 42 percent of the general population is white and 37 percent is African American. Thus, it is not surprising that the Chicago DA\&A sample has a higher proportion of African-American participants than the Portland sample. However, the fact that the Chicago sample was 90 percent African American cannot be completely explained by the distribution of ethnicity in the general population. The distribution of poverty and substance abuse 
Table 2

Participant Baseline Demographics by Study Site

\begin{tabular}{|c|c|c|c|c|c|c|c|c|c|}
\hline & $\begin{array}{l}\text { Chicago } \\
(N=255)\end{array}$ & $\begin{array}{l}\text { Portland } \\
(N=182)\end{array}$ & $\begin{array}{c}\text { Detroit } \\
(N=201)\end{array}$ & $\begin{array}{c}\text { Seattle } \\
(N=321)\end{array}$ & $\begin{array}{l}\text { Santa Clara } \\
\text { County } \\
(N=66)\end{array}$ & $\begin{array}{l}\text { Los Angeles } \\
(N=286)\end{array}$ & $\begin{array}{l}\text { San Joaquin } \\
\text { County } \\
(N=154)\end{array}$ & $\begin{array}{l}\text { Alameda } \\
\text { County } \\
(N=146)\end{array}$ & $\begin{array}{c}\text { San } \\
\text { Francisco } \\
(N=153)\end{array}$ \\
\hline $\begin{array}{l}\text { Gender:** } \\
\text { Female } \\
\text { Ethnicity:*** }\end{array}$ & $30.2 /(\mathrm{SD})$ & $46.2 /(\mathrm{SD})$ & $37.3 /(\mathrm{SD})$ & $37.7 /(\mathrm{SD})$ & $40.9 /(\mathrm{SD})$ & $35.7 /(\mathrm{SD})$ & $53.2 /(\mathrm{SD})$ & $43.2 /(\mathrm{SD})$ & $30.1 /(\mathrm{SD})$ \\
\hline African American or & & & & & & & & & \\
\hline black & 90.6 & 22.5 & 74.6 & 29.3 & 6.1 & 51.7 & 33.8 & 62.3 & 42.5 \\
\hline White & 4.7 & 60.4 & 18.4 & 47.4 & 42.4 & 25.5 & 47.4 & 22.6 & 38.6 \\
\hline Hispanic & 3.9 & 1.1 & 3.5 & 2.5 & 43.9 & 13.6 & 25.3 & 10.3 & 11.8 \\
\hline Other & .8 & 15.9 & 3.5 & 19.6 & 7.6 & 8.7 & 16.2 & 4.8 & 6.5 \\
\hline Age (mean) $* * *$ & $\begin{array}{l}42.5 \\
(8.4)\end{array}$ & $\begin{array}{l}41.8 \\
(7.4)\end{array}$ & $\begin{array}{l}43.5 \\
(6.7)\end{array}$ & $\begin{array}{l}43.1 \\
(8.1)\end{array}$ & $\begin{array}{l}43.6 \\
(7.5)\end{array}$ & $\begin{array}{l}44.2 \\
(8.1)\end{array}$ & $\begin{array}{l}40.4 \\
(8.2)\end{array}$ & $\begin{array}{l}44.0 \\
(8.4)\end{array}$ & $\begin{array}{l}45.1 \\
(7.7)\end{array}$ \\
\hline $\begin{array}{l}\text { Education in years } \\
(\text { mean })^{* *}\end{array}$ & $\begin{array}{l}10.5 \\
(2.1)\end{array}$ & $\begin{array}{l}10.7 \\
(2.2)\end{array}$ & $\begin{array}{l}10.3 \\
(2.1)\end{array}$ & $\begin{array}{l}10.7 \\
(2.3)\end{array}$ & $\begin{array}{l}10.9 \\
(2.3)\end{array}$ & $\begin{array}{l}10.9 \\
(2.5)\end{array}$ & $\begin{array}{l}10.6 \\
(1.9)\end{array}$ & $\begin{array}{l}11.3 \\
(2.0)\end{array}$ & $\begin{array}{l}11.0 \\
(2.4)\end{array}$ \\
\hline Marital status: $* * *$ & & & & & & & & & \\
\hline Married & 6.7 & 7.1 & 3.0 & 6.5 & 15.2 & 8.0 & 9.1 & 9.6 & 5.9 \\
\hline Widowed & 4.7 & 3.8 & 7.5 & 4.0 & 1.5 & 5.6 & 6.5 & 7.5 & 7.8 \\
\hline $\begin{array}{l}\text { Divorced, separated } \\
\text { Single (never }\end{array}$ & 32.9 & 55.5 & 36.3 & 49.2 & 48.5 & 44.1 & 48.1 & 32.9 & 36.6 \\
\hline $\begin{array}{l}\text { married) } \\
\text { Monthly legal income }\end{array}$ & 55.7 & 33.5 & 52.7 & 39.9 & 34.8 & 42.3 & 36.4 & 50.0 & 48.4 \\
\hline$(\$ ; \text { mean })^{a, * * *}$ & $\begin{array}{c}569.13 \\
(296.62)\end{array}$ & $\begin{array}{c}584.30 \\
(397.24)\end{array}$ & $\begin{array}{c}531.64 \\
(402.52)\end{array}$ & $\begin{array}{c}600.10 \\
(395.87)\end{array}$ & $\begin{array}{c}699.98 \\
(317.73)\end{array}$ & $\begin{array}{c}653.53 \\
(387.98)\end{array}$ & $\begin{array}{c}872.54 \\
(939.84)\end{array}$ & $\begin{array}{c}702.67 \\
(317.29)\end{array}$ & $\begin{array}{c}761.13 \\
(356.03)\end{array}$ \\
\hline $\begin{array}{l}>2 \text { Medical problems } \\
\text { past month }{ }^{\mathrm{b}, * * *} \\
>2 \text { Psychiatric symp- }\end{array}$ & 68.2 & 78.6 & 79.6 & 81.9 & 78.8 & 86.0 & 75.3 & 80.8 & 77.8 \\
\hline toms past month ${ }^{\mathrm{c}, * * *}$ & 61.2 & 71.4 & 61.2 & 74.1 & 75.8 & 83.6 & 70.1 & 81.5 & 71.2 \\
\hline HIV positive $* * *$ & 3.5 & 3.3 & 3.0 & 3.1 & .0 & 1.4 & 2.6 & 4.1 & 10.5 \\
\hline
\end{tabular}




\begin{tabular}{|c|c|c|c|c|c|c|c|c|c|}
\hline $\begin{array}{l}\text { In drug treatment at } \\
\text { least } 4 \text { weeks in past } \\
6 \text { months*** }\end{array}$ & 26.3 & 46.2 & 26.9 & 39.3 & 36.4 & 42.7 & 31.2 & 33.6 & 56.9 \\
\hline $\begin{array}{l}>=\text { Daily alcohol use } \\
\text { in past } 6 \text { months } * * * \\
>=\text { Daily cocaine or }\end{array}$ & 16.5 & 13.7 & 23.4 & 12.1 & 15.2 & 20.6 & 11.0 & 19.2 & 13.7 \\
\hline $\begin{array}{l}\text { heroin use in past } 6 \\
\text { months } s^{\mathrm{e}, *}\end{array}$ & 12.9 & 7.7 & 5.5 & 8.4 & 4.5 & 10.5 & 10.4 & 7.5 & 8.5 \\
\hline $\begin{array}{l}\text { Commit any crime in } \\
\text { past } 6 \text { months**** }\end{array}$ & 28.6 & 36.7 & 18.1 & 25.6 & 16.7 & 28.3 & 35.1 & 30.1 & 21.6 \\
\hline
\end{tabular}

Note. - Total $N=1,764$. All figures are based on self-reported data collected at baseline between December 1996 and May 1997 , and are percentages unless otherwise noted. Comparisons of interval-level data are made using one-way ANOVAs. Comparisons of nominal data are made using Pearson's $\chi^{2}$ test and Cramer's $\mathrm{V}$ to lessen the effect of sample size. In all cases, the two tests yield similar significance results.

${ }^{a}$ Legal income excludes income from any illegal sources.
${ }^{\mathrm{b}}$ Medical problems include sight or hearing problems, blood and heart diseases, hepatitis and jaundice, sexually transmitted diseases, nervous

conditions, muscle and bone disease, dental problems, burns and wounds.

${ }^{\mathrm{e}}$ Includes all forms of cocaine, such as powder and crack cocaine.

$* \mathrm{p}<.05$.

$* * \mathrm{p}<.01$.
$* * * \mathrm{p}<.001$ 
doubtless also played an important role in the demographic composition of each site's DA\&A population and sample.

Underlying population differences notwithstanding, differences in sampling frames constitute another source of variation among sites. Seven sites based their sampling frames on lists of DA\&A recipients obtained from the state RMAs. The remaining two sites, Chicago and Los Angeles, secured lists of DA\&A beneficiaries from regional SSA offices. In comparison to the SSA lists, which included the entire DA\&A population within a certain time frame, the RMA lists included only active DA\&A recipients. That is, the RMA lists included only those DA\&A recipients who maintained contact with the RMA and who participated in drug treatment if the RMA assessment showed it was warranted (see Wittenburg et al. 2003). DA\&A recipients were dropped from RMA lists if they did not respond to repeated contact attempts or if they had completed treatment and were awaiting a continuing disability review. The extent to which recipients were dropped from RMA lists and the consistency with which the dropping occurred vary by site (Hunt and Baumohl 2003a; Wittenburg et al. 2003). Excepting Seattle, where the RMA lists covered 93 percent of the DA\&A population, and Portland, where the coverage rate was only 48 percent, the sampling frames at sites using the RMA lists included about two-thirds of the eligible population (Choudhry and Helba 2003).

Differences in recruitment rates and sampling fractions are additional sources of variation among sites. The recruitment rates for this study varied from a low of 56 percent in Chicago to a high of 75 percent in Los Angeles, with most sites averaging near 66 percent (Swartz, Tonkin, et al. 2003). The causes of this variation are not clear. Variations may be due to differences in the accessibility of the DA\&A population at each site or perhaps to differences in the vigor of recruitment efforts. Additionally, while the small numbers of SSI DA\&A recipients in Stockton and Portland allowed these sites to sample close to 100 percent of the individuals in their sampling frames, Chicago had an SSI DA\&A population of 14,000 in 1996. Therefore, the sampling fractions in Chicago and other large sites such as Los Angeles and Detroit were much lower than elsewhere.

Because of these sampling and recruitment issues, David Wittenburg and associates (2003) study the extent to which each site's sample was representative of the corresponding local population. Using a nationally complete data set of all DA\&A recipients as of March 1, 1996 (provided by the SSA), they also compare the pooled study panel (i.e., all interviewed participants) to three groups: the pooled study sample (i.e., all recruited participants), the pooled DA\&A population of the study sites, and the national DA\&A population. Table 3, which is based on data collected by the SSA, shows that while the aggregate DA\&A study panel and study sample are not too dissimilar from the aggregate population 
Table 3

Demographic and Program Characteristics of the Pooled SSI Study Panel and Sample, the Multisite DA\&A Population, and the National DA\&A Population

\begin{tabular}{|c|c|c|c|c|}
\hline Characteristic & $\begin{array}{l}\text { SSI Study } \\
\text { Panels } \\
\text { (Weighted) }^{\mathrm{a}}\end{array}$ & $\begin{array}{l}\text { SSI Study } \\
\text { Samples } \\
\text { (Weighted) }^{\mathrm{b}}\end{array}$ & $\begin{array}{l}\text { Multisite } \\
\text { DA\&A } \\
\text { Population }^{c}\end{array}$ & $\begin{array}{l}\text { National } \\
\text { DA\&A } \\
\text { Population }^{\mathrm{d}}\end{array}$ \\
\hline Number & 1,973 & 2,909 & 29,455 & 114,649 \\
\hline Percent SSI only & $92.8^{\mathrm{e}}$ & 92.0 & 100.0 & 100.0 \\
\hline \multicolumn{5}{|l|}{ Gender: } \\
\hline Male & 67.0 & 69.3 & 68.4 & 66.6 \\
\hline \multicolumn{5}{|l|}{ Age (years): } \\
\hline $18-29$ & 5.2 & 6.4 & 5.6 & 8.0 \\
\hline 30-39 & 29.7 & 27.4 & 28.0 & 30.0 \\
\hline $40-49$ & 44.1 & 42.8 & 41.4 & 38.4 \\
\hline $50-59$ & 21.1 & 21.5 & 20.0 & 18.9 \\
\hline Other & .0 & 1.8 & 5.0 & 4.7 \\
\hline \multicolumn{5}{|l|}{ Race: } \\
\hline White & 15.0 & 15.6 & 14.8 & 38.0 \\
\hline Black & 69.3 & 67.5 & 68.6 & 43.2 \\
\hline Other or unreported & 15.8 & 16.9 & 16.5 & 18.8 \\
\hline \multicolumn{5}{|l|}{ Addiction: } \\
\hline Alcohol only & 33.2 & 33.7 & 33.1 & 51.4 \\
\hline Drug only & 15.5 & 15.6 & 16.8 & 17.7 \\
\hline Both & 51.3 & 50.6 & 50.1 & 30.8 \\
\hline \multicolumn{5}{|l|}{ Living arrangement: } \\
\hline Own household & 97.8 & 97.5 & 96.6 & 93.7 \\
\hline Other & 2.2 & 2.5 & 3.4 & 6.3 \\
\hline \multicolumn{5}{|l|}{ SSA monthly payment $(\$)$ : } \\
\hline $0-299$ & 13.1 & 10.1 & 9.2 & 11.0 \\
\hline $300-499$ & 75.4 & 77.2 & 79.9 & 75.1 \\
\hline 500 or more & 11.5 & 12.6 & 10.9 & 13.8 \\
\hline \multicolumn{5}{|l|}{$\begin{array}{l}\text { State supplement per } \\
\text { month }(\$) \text { : }\end{array}$} \\
\hline None & 71.2 & 71.8 & 66.3 & 64.0 \\
\hline $0-49$ & 4.2 & 4.3 & 4.3 & 14.1 \\
\hline 150 or more & 24.6 & 23.9 & 29.4 & 21.9 \\
\hline \multicolumn{5}{|l|}{$\begin{array}{l}\text { Length of time on SSI } \\
(\text { years })::^{f}\end{array}$} \\
\hline$<1$ & 2.5 & 2.4 & 2.6 & 6.1 \\
\hline $1-2$ & 27.9 & 27.8 & 26.2 & 33.4 \\
\hline $3-5$ & 54.1 & 52.7 & 53.1 & 45.0 \\
\hline 5 or more & 15.3 & 17.0 & 18.0 & 15.5 \\
\hline \multicolumn{5}{|l|}{ Representative payee: } \\
\hline \multicolumn{5}{|l|}{$\begin{array}{l}\text { Spouse, child, parent, } \\
\text { grandparent, or other }\end{array}$} \\
\hline $\begin{array}{l}\text { Public official, social } \\
\text { agency, mental agency, } \\
\text { nonmental institution }\end{array}$ & 15.0 & 15.3 & 16.2 & 19.7 \\
\hline Other & 25.8 & 27.0 & 28.3 & 26.6 \\
\hline No representative payee & .1 & .2 & .3 & .7 \\
\hline \multicolumn{5}{|l|}{ Decision level: } \\
\hline Initial award & 44.0 & 46.9 & 48.8 & 53.8 \\
\hline Reconsideration & 16.6 & 17.2 & 17.9 & 14.4 \\
\hline Hearing & 39.2 & 35.6 & 32.9 & 31.4 \\
\hline $\begin{array}{l}\text { Appeals council or federal } \\
\text { court }\end{array}$ & .2 & .3 & .4 & .4 \\
\hline
\end{tabular}


Table 3 (Continued)

\begin{tabular}{lcccc}
\hline & $\begin{array}{c}\text { SSI Study } \\
\text { Panels } \\
\text { (Weighted) }^{\mathrm{a}}\end{array}$ & $\begin{array}{c}\text { SSI Study } \\
\text { Samples } \\
\text { (Weighted) }\end{array}$ & $\begin{array}{c}\text { Multisite } \\
\text { DA\&A } \\
\text { Population }^{\mathrm{c}}\end{array}$ & $\begin{array}{c}\text { National } \\
\text { DA\&A } \\
\text { Population }^{\mathrm{d}}\end{array}$ \\
\hline Primary impairment category: & & & & \\
$\quad$ Psychiatric & 71.8 & 72.1 & 73.9 & 76.0 \\
Substance abuse & 63.1 & 63.4 & 62.5 & 65.3 \\
Other & 4.5 & 4.6 & 4.4 & 6.5 \\
Unknown & 23.7 & 23.3 & 21.6 & 17.4 \\
\hline
\end{tabular}

Source.-Wittenburg et al. 2003, pp. 123-36. Copyright 2003 by Federal Legal Publications, Inc. Reprinted and adapted with permission.

NotE.-Unless otherwise indicated, each number reported is a column percent. Percents may not add to 100 due to rounding or a small number of missing values. All data are based on information collected by the Social Security Administration.

${ }^{a}$ The SSI study panels include all SSI recipients recruited and interviewed during the baseline phase of the study. Study panels exclude those recruited but not interviewed, and are weighted to adjust for differences in sampling and recruitment rates among the sites.

${ }^{b}$ The SSI study samples include all those selected and recruited to the study as well as those selected but not interviewed. Samples are weighted to adjust for differences in the sampling and recruitment rates among the sites.

' Total pooled population of SSI DA\&A beneficiaries in the nine SSI study sites' catchment areas.

${ }^{\mathrm{d}}$ Number of SSI beneficiaries in DA\&A as of 1996. Data abstract provided by the SSA.

${ }^{\mathrm{e}}$ The total multisite study panel $N$ based on these calculations is 1,973 participants, though the final $N$ was actually 1,764 participants. The discrepancy is due to the effects of weighting and to the elimination from the final analytic sample of participants found to be ineligible after the baseline interview was conducted.

${ }^{\mathrm{f}}$ This variable is measured as the duration of time since first receiving SSI. The date of eligibility for those who receive allowances is determined by the date of application.

represented by the nine study sites, they are strikingly dissimilar to the national SSI DA\&A population. Compared to that national population, the pooled study panel and sample include, in particular, a higher proportion of African Americans, a higher proportion of participants between 30 and 49 years of age, and a higher proportion of participants classified as dependent on both alcohol and other drugs. Wittenburg and associates (2003) also note differences between populations and samples at the site level (not shown in table 3); they attribute these differences to recruitment rates and the incomplete RMA sampling frames. In particular, African Americans were underrepresented in Detroit, San Francisco, and San Jose, whereas women were underrepresented in the Portland sample. Based on their analyses, Wittenburg and associates (2003) conclude that the aggregate DA\&A panel (i.e., those interviewed) was reasonably representative of the population of former SSI DA\&A recipients for the aggregate study area but not of the national population. They also note that there were discrepancies between the local panel and population for some of the sites, particularly those sites that used an RMA's list as a sampling frame. 
To improve the degree to which each site sample and the aggregate sample were representative of their respective populations, G. Hussain Choudhry and Cynthia Helba (2003) developed a set of weights for use in the statistical analyses. These weights are designed to adjust for differences in sampling rates among sites, as well as for demographic differences between each site sample and the corresponding local DA\&A population. The articles summarized here from the multisite study are based on analyses that use the weighted data, normalized and adjusted to avoid inflating the sample size. Where possible, several studies (Campbell et al. 2003; Norris et al. 2003; Swartz, Campbell, et al. 2003) also use replicate-derived variance estimates (i.e., created by averaging the statistical results from repeated samplings of randomly selected subgroups of the original sample) to further correct for sampling and design effects. Additionally, because of the variation in recruitment and sampling among the sites, the very different demographic compositions of the DA\&A populations across sites (as shown in table 2), and the differences in local safety nets, all analyses based on the multisite data include site effects in their multivariate statistical models to both measure and control for the effects of site differences.

\section{Measures}

The questionnaires administered at each site and interview wave included a core set of 582 questions derived primarily from the Global Appraisal of Individual Needs (GAIN; Dennis et al. 1996), the Community Childhood Hunger Identification Project food security questions (Wehler, Scott, and Anderson 1996), and the Addiction Severity Index (ASI; McLellan et al. 1992). Administered in interviews of 60-90 minutes, the core questions covered demographic characteristics, experience with the receipt of SSI benefits, and multiple functional areas. The functional areas include those possibly affected by the termination of disability benefits: medical and psychiatric problems and treatment, alcohol and other drug use, substance abuse treatment, medical insurance status, barriers to receiving treatment, legal system involvement, criminal activity, food acquisition and hunger, living arrangements, victimization, employment status, sources of income, SSI requalification attempts and status, and representative payee status.

In addition to self-reported information, sites in Chicago, Los Angeles, and Seattle added urine testing for five drugs to the study protocol for all participants at the 1-year, 18-month, and 2-year follow-ups. The urine tests were used to check the validity of self-reported drug use and to get a second measure of recent drug use. The five tested drug classes include cannabinoids, cocaine, opiates, amphetamines, and phencycli-

dine. For four of the five classes, the three sites used detection thresholds established by the National Institute on Drug Abuse (NIDA). For can- 
nabinoids, Seattle used a lower threshold $(20 \mathrm{ng} / \mathrm{ml})$ than the NIDA recommended figure of $50 \mathrm{ng} / \mathrm{ml}$ and Los Angeles used a higher threshold $(100 \mathrm{ng} / \mathrm{ml})$.

\section{Procedures}

Research staff recruited participants through introductory letters informing them of the study and the opportunity to be interviewed about their experiences with the DA\&A program. Except in Portland and Stockton, where the small sizes of the DA\&A populations allowed staff to target everyone in the population for recruitment, simple random sampling was employed to select study recruits from each site's sampling frame.

Baseline data collection began in December 1996, with follow-up interviews conducted every 6 months over a 2 -year period, yielding a possible total of five interviews per participant. Each interview wave lasted 3 to 4 months. Most interviews were conducted face-to-face by local interviewers, using paper and pencil. Beginning with the third interview wave, interviewers in Chicago used laptop computers. The retention rate for the study was very high, with 92 percent of the sample completing three or more follow-up interviews, and 90 percent ( $n=1,586$ ) completing the 2-year follow-up.

As the research questions imply, the analyses of the multisite data attempted to assess the effects of terminating the DA\&A program by comparing outcomes for those who requalified for SSI with those of participants who did not. As participants could not be randomly assigned to these conditions, they were placed in groups after completion of the application process for requalification. Placement was based on the pattern of their SSI requalification status, income sources, and income levels across the follow-up interviews. Those participants who reported at the majority of their follow-up interviews that they were receiving SSI disability benefits for impairments other than alcoholism or drug addiction were counted as requalifiers. Those who did not requalify were further divided into comparison groups based on whether they reported assistance from other sources, such as TANF, general assistance, or veterans' benefits (as in the study of economic effects by Campbell et al. 2003), and whether they were able to replace at least 50 percent (e.g., Norris et al. 2003) or 75 percent (e.g., Swartz and Martinovich 2003b) of baseline income. The exact sample size for any given analysis varied. Generally, it was not possible to use data from between 5 and 10 percent of the 1,764 participants interviewed at baseline, because they participated in too few interviews or reported an erratic requalification status or income level across follow-up periods. Small groups of participants also had missing data for other covariates or outcome measures used in a particular analysis. 


\section{Results}

\section{Requalification Rates and Income Replacement}

By April 1999, between 35 and 43 percent of former DA\&A recipients in the multisite sample had requalified for SSI benefits (Campbell et al. 2003). This variation results from small differences in the criteria for assessing requalification status (e.g., requalified at any follow-up; requalified at most follow-ups, etc.) and the particular subsample used in the analysis. The range is consistent with the requalification rate of about 40 percent estimated for the national SSI DA\&A population using analyses that control for an expected rate of program attrition (e.g., due to death, employment, administrative termination of benefits) that would have occurred even in the absence of program termination (see Lewin Group, Inc., and Westat, Inc. 1998; Davies et al. 2000). However, the multisite and national estimates are both well below the Congressional Budget Office's (CBO) projected requalification rate of 75 percent, offered prior to the termination of the DA\&A program (SolomonFears 1997).

The CBO's estimate was likely based on SSA records showing the proportion of DA\&A recipients with other medically eligible conditions. However, Katherine Watkins, Deborah Podus, and Emilia Lombardi (2001) compare the SSA records of requalifiers with those who did not requalify and find that the documented presence of a medical or psychiatric condition is only weakly related to requalification status. Because research after the fact cannot reproduce the complex SSI medical eligibility review or elucidate an applicant's persistence with the process, we would not expect to find a dramatic correlation between rough diagnostic data and continuing eligibility. Still, nonmedical factors do appear to have affected the requalification rate, though it is not possible to quantify them. Questionnaire and life history data for the multisite study suggest that these nonmedical factors include the local availability of assistance and advocacy for reapplication, the intense desire of some disability recipients to get off welfare, whatever the cost to them, and local variation in how redetermination criteria were applied. Narrative data also reveal that some DA\&A beneficiaries did not attempt to requalify because they mistook official communications about the end of the DA\&A program to indicate an SSA determination that they were no longer eligible for disability benefits of any kind (Scott and Baumohl 2003).

Among all participants, 20 percent were able to secure income assistance from other sources while 37 percent reported no consistent source of income assistance over the 2-year follow-up. As shown in figure 1, there is considerable intersite variation on all of these rates (Campbell et al. 2003). For example, requalification rates vary from a low of 25 


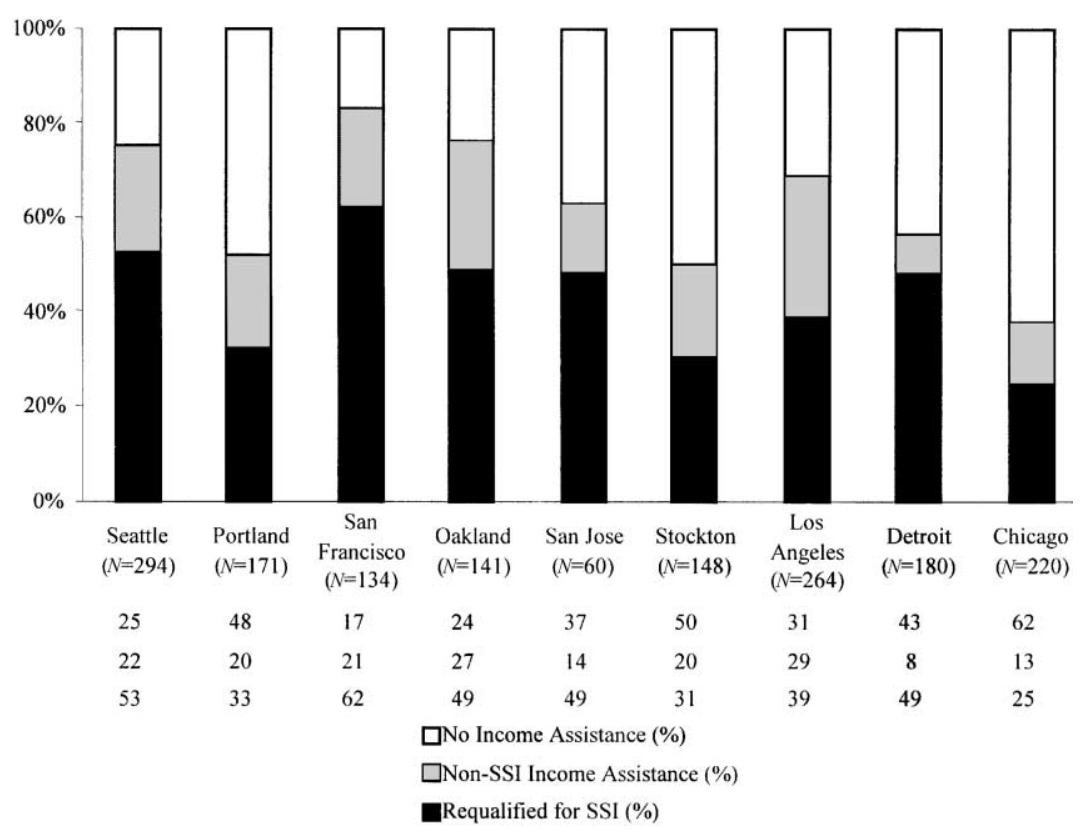

FIG. 1.-Former SSI DA\&A recipients' principal income source for the 24-month followup period. SourcE.-Campbell et al. 2003, pp. 195-240. Copyright 2003 by Federal Legal Publications, Inc. Reprinted and adapted with permission. NotE.-Total $N=1,612$. The overall percentages for each income category are as follows: 43 percent requalified for SSI; 20 percent received non-SSI income assistance; and 37 percent received no income assistance for the majority of the follow-up period.

percent in Chicago to a high of 62 percent in San Francisco. The reasons for the large intersite variation in requalification rates are unknown. Richard Scott and Jim Baumohl (2003) stress the uneven presence and effectiveness of local advocacy organizations as possible explanations.

Focusing on the 37 percent of the sample that did not requalify for SSI or obtain other income assistance, Kevin Campbell, Jim Baumohl, and Sharon Hunt (2003) examine employment rates and earnings over the follow-up period. By defining employment liberally as any reported income from employment in the 6 months preceding the interview, they find that employment rates rose from 20 percent at baseline to between 40 percent and 60 percent by the 2-year follow-up for those in the multisite sample who lost all income assistance. However, the incomes earned were very modest, reflecting widespread underemployment. Median monthly earned income among those employed at 24 months ranged from $\$ 333$ in Portland to over $\$ 1,000$ in San Francisco and Stockton. Less than 25 percent of the respondents at six of the nine sites reported earnings equal to or greater than $\$ 500$ per month, the approximate amount lost when SSI benefits were terminated. Thus, 
while larger numbers of former DA\&A recipients gained sporadic employment over time, their earnings rarely offset the loss of cash benefits.

\section{Housing and Hunger}

The meager value of these earnings is brought into greater focus when compared to local housing costs. Campbell and associates (2003) examine income of those who did not requalify across sites, finding that only 28-40 percent earned even half the estimated fair market rent for a studio apartment in their area. In other words, the majority of those who lost DA\&A benefits, employed or not, were unable to afford housing on their own (see Cancian et al. 2002 for similar reports of high rates of poverty among employed women leaving the Aid to Families with Dependent Children program). This housing income shortage was likely exacerbated by the rapid rise in the price of rental units in many of the study sites during the late 1990s (see Anderson et al. 2002).

Given the gap between income and fair market rents, it is not surprising that the loss of SSI affected the housing status of many former DA\&A recipients. At the 2-year follow-up, those who lost SSI and did not replace at least 50 percent of baseline income, whether through employment or income assistance (43 percent), reported higher rates of residential doubling up, that is, living with someone else at the time of any follow-up interview and not paying any rent or receiving a housing subsidy (26 percent), than did SSI requalifiers (3 percent) and those who replaced at least half of their baseline income (13 percent; Norris et al. 2003). In multivariate logistic regression analyses controlling for site and demographic differences, Jean Norris and colleagues (2003) find that even those who lost SSI but eventually replaced its cash value were five times more likely than those who retained benefits to report residential doubling up during the follow-up period $(p<.001)$. Those who lost but did not replace their SSI income were almost 11 times more likely than requalifiers to report residential doubling up $(p<$ .001). A similar, though less pronounced pattern of results obtains for the other hardship measures examined by Norris and associates (2003). Compared to those who retained SSI (table 4), those who lost SSI and were unable to replace at least half of the lost income had twice the odds of reporting hunger $(p<.05)$ and homelessness $(p<.01)$ during the follow-up period. In contrast to the findings on employment and income replacement, multivariate logistic regression models do not find large or consistent effects for site on these hardship measures.

There was a more general trend toward improvement in both housing and hunger status, regardless of SSI status or income. With the primary exception of residential doubling up, the rates of material hardship experienced by former SSI DA\&A recipients peaked at the 1-year followup in almost every measured category of housing and hunger and de- 
Table 4

Frequency Distributions of Material Hardships at Baseline, 12 Months, 24 Months, and at Anytime during the 2-Year Follow-Up, by SSI Status and REPLACEMENT INCOME (\%)

\begin{tabular}{|c|c|c|c|c|}
\hline Outcomes & Baseline & 12 Months & 24 Months & $\begin{array}{l}\text { Any Follow-Up } \\
\text { Interview }\end{array}$ \\
\hline \multicolumn{5}{|l|}{ Residential doubling-up $* * *$} \\
\hline Sample: & 3.4 & 16.2 & 13.4 & 32.8 \\
\hline Kept SSI & 3.3 & 3.8 & 3.2 & 11.0 \\
\hline $\begin{array}{l}\text { Replaced } 50 \% \text { or more } \\
\text { income }\end{array}$ & 3.0 & 12.7 & 13.1 & 33.7 \\
\hline $\begin{array}{l}\text { Replaced less than } 50 \% \\
\text { income }\end{array}$ & 4.0 & 34.2 & 25.9 & 58.3 \\
\hline \multicolumn{5}{|l|}{ Homelessness } \\
\hline Sample: & 3.1 & 4.5 & 4.7 & 13.0 \\
\hline Kept SSI & 3.0 & 2.4 & 3.0 & 9.4 \\
\hline $\begin{array}{l}\text { Replaced } 50 \% \text { or more } \\
\text { income }\end{array}$ & 2.0 & 3.0 & 5.3 & 12.1 \\
\hline $\begin{array}{l}\text { Replaced less than } 50 \% \\
\text { income }\end{array}$ & 4.3 & 8.2 & 6.4 & 17.9 \\
\hline \multicolumn{5}{|l|}{ Emergency food use $\mathrm{a}^{\mathrm{a}}$} \\
\hline Sample: & 22.7 & 18.0 & 13.8 & 37.8 \\
\hline Kept SSI & 21.3 & 16.7 & 13.8 & 32.4 \\
\hline $\begin{array}{l}\text { Replaced } 50 \% \text { or more } \\
\text { income }\end{array}$ & 21.1 & 14.3 & 10.6 & 36.7 \\
\hline $\begin{array}{l}\text { Replaced less than } 50 \% \\
\text { income }\end{array}$ & 26.0 & 22.8 & 16.7 & 45.4 \\
\hline \multicolumn{5}{|l|}{ Hunger in 7 days $^{\mathrm{a}, *}$} \\
\hline Sample: & 21.3 & 13.3 & 10.2 & 32.2 \\
\hline Kept SSI & 16.1 & 10.4 & 7.9 & 26.6 \\
\hline $\begin{array}{l}\text { Replaced } 50 \% \text { or more } \\
\text { income }\end{array}$ & 22.8 & 12.5 & 6.9 & 30.8 \\
\hline \multicolumn{5}{|l|}{$\begin{array}{l}\text { Hunger, day without food in } 30 \\
\text { days }^{\mathrm{a}, *}\end{array}$} \\
\hline Sample: & 27.7 & 22.7 & 19.3 & 45.6 \\
\hline Kept SSI & 21.8 & 18.6 & 20.0 & 42.5 \\
\hline $\begin{array}{l}\text { Replaced } 50 \% \text { or more } \\
\text { income }\end{array}$ & 26.9 & 18.3 & 14.5 & 43.6 \\
\hline $\begin{array}{l}\text { Replaced less than } 50 \% \\
\text { income }\end{array}$ & 35.5 & 31.5 & 22.9 & 51.0 \\
\hline
\end{tabular}

Source. - Norris et al. 2003, pp. 241-75. Copyright 2003 by Federal Legal Publications, Inc. Reprinted and adapted with permission.

NotE.-All figures are percents.

${ }^{\text {a }}$ Figures in boldface indicate functional areas that were stable (i.e., less than $1 \%$ change) or improved between baseline and the 2-year follow-up interview for all participants.

$* \quad p<.01$ baseline differences among the three groups as determined by $\chi^{2}$ tests.

$* * * \quad p<.001$ for $t$-test of odds ratios from logistic regression model of income replacement groups compared to those retaining SSI. 


\section{Social Service Review}

clined thereafter to at or below baseline levels (the shaded numbers in table 4). For example, at baseline, 26 percent of those who did not replace their lost SSI income reported experiencing hunger in the past 7 days. By the 24-month follow-up, this figure dropped to less than 16 percent. However, even with the low attrition rate for the multisite study, these results could be mediated by a disproportionate loss to follow-up of participants who lacked stable housing, owing to the greater difficulty in locating such participants.

Despite the potential concerns raised by these figures, the data reported by Norris and associates (2003) also show that the majority of former DA\&A recipients did not report problems with housing or hunger. For the minority who did, primarily those who did not requalify and failed to replace the lost income, the data indicate a pattern of housing and food instability (i.e., fluctuating between homelessness and being domiciled, and between acquiring adequate food and being hungry from one interview to another) over the follow-up period. For any single follow-up period, the differences were statistically significant but not large between those not replacing the lost income and those who requalified. Over time, a greater proportion of those who did not requalify experienced homelessness and hunger. Their ability to find employment, maintain secure housing, and obtain enough food was more variable than for other participants, though the gradual improvement in all these areas suggests that many achieved more stability in housing and food acquisition as time went on.

\section{Health-Care Access}

The loss of Medicaid benefits by those failing to requalify for SSI is associated with lower use of medical and psychiatric treatment services (Podus, Barron, et al. 2003). However, there is considerable site variation in rates of insurance loss among those who did not requalify for SSI benefits, from a low of about 16 percent uninsured in Portland to a high of about 47 percent in Chicago (Podus, Barron, et al. 2003). Deborah Podus and colleagues attribute these site differences to differential rates of SSI requalification and to differences in local availability of alternative sources of insurance for those who lost SSI. Controlling for the severity of medical and psychiatric disorders as well as other adjusters, these authors find that, in five of nine sites, those who lost SSI and were uninsured were about half as likely to receive medical care as those who requalified for SSI (results varied by site from $p<.001$ to $p<.05$ ). In six of nine sites, those who lost SSI and medical insurance were 20-60 percent less likely to report receiving mental health care, compared to those who retained SSI (results varied by site from $p<.001$ to $p<.05$ ). Unexpectedly, the use of outpatient medical and mental health services by all study respondents dropped by about 10-15 percent over the 
course of the study. This remains the case regardless of insurance status and after controlling for both severity of need and demographic factors. However, those who did not requalify and who were uninsured through any other means had the steepest rates of decline in service utilization. Contrary to the study hypothesis, this finding includes emergency room visits. In addition, though the majority of sites did show greater declines in medical and psychiatric service utilization among those who did not requalify for SSI benefits than among those who did, averaging across all sites, some of which did not have differential declines in service utilization, reduced the magnitude of these effects.

The authors conclude that decreased access to health-care services, particularly among those who did not requalify for benefits, was mitigated to varying degrees by the availability of local services for the indigent (Podus, Barron, et al. 2003). The variation in local contexts may also have been why the loss of SSI benefits and Medicaid coverage had no large overall differential effects on health-care access when the results were averaged across sites. So too, such variation may explain why the loss of SSI and Medicaid did not cause a shift from less expensive sources of primary care, such as physicians' offices or health clinics, to more expensive sources, such as emergency rooms.

\section{Drug Treatment Participation Rates}

As noted, the mandate to participate in substance abuse treatment was a part of the SSI DA\&A program from its inception in 1974, although it was added to DI requirements only in 1994. However, as the SSA lacked the means to monitor treatment participation and the funds to subsidize it where state Medicaid plans did not, this mandate was never fully enforced. With the 1994 legislative changes, a much larger number of RMAs were contracted to arrange and monitor treatment participation, as well as to report noncompliance to the SSA. The monitoring of treatment increased rapidly through 1995 as the new RMAs hurried to assess and monitor over 200,000 DA\&A recipients (including those on DI). However, the March 1996 legislation that terminated the DA\&A program caused the SSA to shift its attention from enforcing compliance to notifying recipients of the program's demise and processing requalification applications. Although the RMAs continued to monitor compliance and report to the SSA for the remainder of 1996, the SSA did not bother to terminate or sanction those whom the RMAs reported to be in noncompliance. As Sharon Hunt and Jim Baumohl (2003a) note, DA\&A recipients were essentially given a pass on the treatment mandate for the last 9 months of the program.

Given the timing of legislative changes affecting administration of the DA\&A program, it is not surprising that in the 6 months preceding the baseline interview, only 41 percent of the multisite sample reported 
being in substance abuse treatment of any kind. Such treatment was predominantly methadone maintenance or outpatient drug-free programming (Swartz, Campbell, et al. 2003). To be sure, not all DA\&A recipients were actively using drugs or alcohol during this time. Some, for example, had already completed treatment and were awaiting the continuing disability reviews that never occurred. Hence, the low treatment participation rate at the end of the DA\&A program is likely the result of both treatment completion and nonenforcement of the mandate.

Although it would be useful to assess whether the treatment mandate reduced substance use among the DA\&A recipients in compliance, the design of the study does not allow it. There is no way to determine the pretreatment levels of use for those who entered treatment or to create a meaningful comparison group from the participants who were not treated. Instead, James Swartz, Kevin Campbell, and associates (2003) assess the impact of the 1996 legislation on treatment attrition and enrollment rates. They find that the treatment participation rate declined quickly and sharply once the DA\&A program was terminated. More than 67 percent of those in outpatient treatment at baseline had dropped out of any kind of substance abuse treatment by the end of the study, with the largest proportion of dropouts occurring between baseline and the second follow-up interview. There was a similar decline in participation in methadone maintenance treatment, from 17 percent at baseline to 11 percent at the 2-year follow-up. Across the entire followup period, less than 9 percent of former DA\&A recipients initiated drug treatment. Together, the high attrition and low enrollment rates produced the large decreases in the level of treatment participation.

Using archival data, Swartz, Campbell, and associates (2003) compare the treatment drop-out rate over the course of the study for Seattle DA\&A recipients in outpatient treatment during the multisite study with the drop-out rate for members of the Washington State DA\&A population who were in outpatient substance abuse treatment during the 2 years before termination of the DA\&A program. They find that the Seattle DA\&A recipient group had higher attrition and lower enrollment rates than the Washington State group over a 2 -year period $\left(\chi_{\mathrm{df}=1}^{2}=\right.$ $16.91, p<.001$; hazard ratio $=2.08)$. Although these results are based on Washington State participants only and may not generalize to participants at other sites, they support the interpretation that at least some of the decline in treatment participation found in the multisite study was due to the elimination of the treatment mandate, however laxly enforced, rather than to normal treatment attrition and enrollment rates. 
Prevalence of Alcohol and Illegal Drug Use

As noted, little good data is reported on the levels of alcohol and other drug use among welfare recipients generally and among DA\&A recipients specifically (Pollack et al. 2002). Estimates based on self-reported data from the National Household Survey on Drug Abuse (NHSDA) indicate that some form of illegal drug use in the year prior to the survey was reported by 21 percent of those receiving public aid; 6 percent reported cocaine use (Jayakody, Danziger, and Pollack 2000). Another analysis using NHSDA data controlled for community effects and found that homes with welfare recipients, including SSI recipients, have about a 50 percent greater chance of reporting drug use than households with no welfare recipients (Delva et al. 2000).

Using the self-reported data on alcohol and other drug use at the 2year follow-up, Richard Speiglman and colleagues (2003) report rates of use for the 30 days prior to the survey. Among the most commonly used drugs, the rates were 23 percent for cocaine, 22 percent for marijuana, and 13 percent for heroin. Forty percent of participants reported use of some illegal drug at the 2-year follow-up. Twenty-one percent of participants reported drinking to intoxication within the 30 days prior to the 2-year follow-up. Because self-reported data on illegal drug use are likely to be underestimates of actual use (Magura and Kang 1996; Harrison 1997), Deborah Podus, Eunice Chang, and associates (2003) examine rates using urinalysis results for participants in Chicago, Los Angeles, and Portland. ${ }^{4}$ They find higher rates of illegal drug use among study participants than those reported by Speiglman and associates (2003). With some site variation, about 50 percent of the participants in Los Angeles, Portland, and Chicago tested positive for at least one illegal drug, with 20 percent testing positive for opiate use (primarily heroin) and 29 to 38 percent testing positive for cocaine (Swartz, Hsieh, et al. 2003). These results suggest that illicit drug use among former DA\&A recipients was fairly prevalent; in the case of cocaine, it occurred at almost twice the self-reported rate. Consistent with the self-reported data, the urinalysis results show no significant changes in use over the final 18 months of the study, regardless of participants' SSI status (Swartz, Hsieh, et al. 2003).

If SSI benefits provided ready cash for the purchase of alcohol and illegal drugs, the multisite study should find higher rates of use among those continuing to receive SSI benefits, especially compared to those who did not replace their lost incomes. This is not the case, however, as those who lost cash benefits and did not replace the income had rates of illegal drug use during the follow-up period (as measured by urinalysis results) that are statistically equal to those who retained SSI (Swartz, Hsieh, et al. 2003). In fact, self-reported income, regardless of 


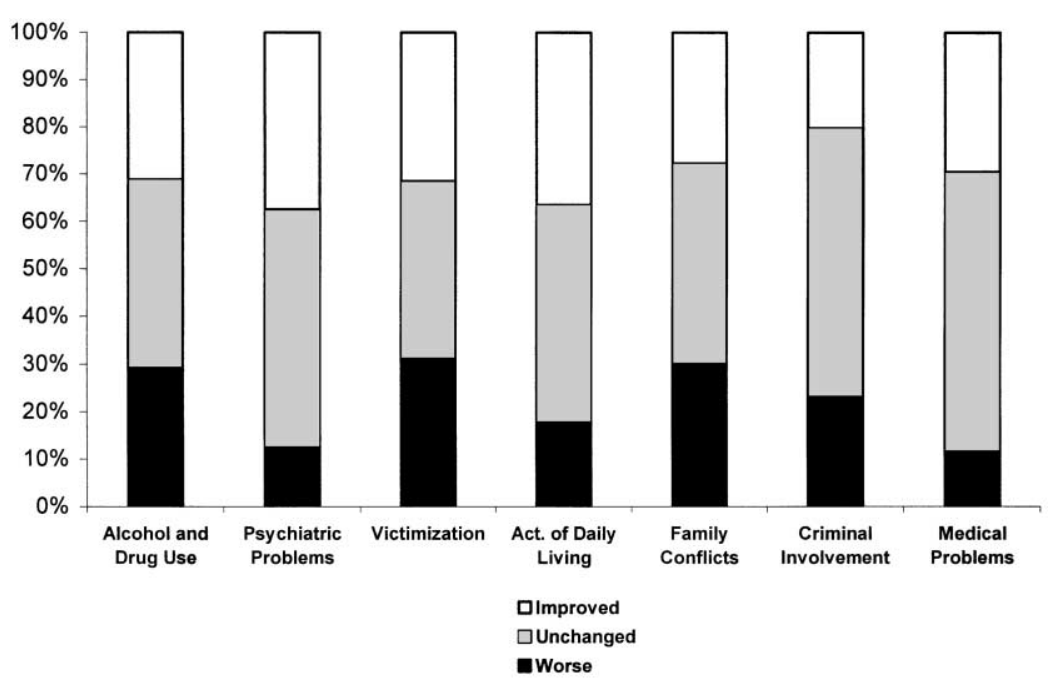

FIG. 2.-Former SSI DA\&A recipients' changes in functioning for the 24-month followup period. Source.-Swartz and Martinovich 2003b, pp. 425-54. Copyright 2003 by Federal Legal Publications, Inc. Reprinted and adapted with permission. Note.-Total $N=1,612$. The overall percentages for each income category are as follows: 43 percent requalified for SSI; 20 percent received non-SSI income assistance; and 37 percent received no income assistance for the majority of the follow-up period. Act. = activities.

source, is not related to illegal drug use. Moreover, in a related finding, James Swartz, Chang-ming Hsieh, and Jim Baumohl (2003) find that having a representative payee did not affect whether a respondent used illegal drugs. Those assigned a representative payee after requalification for SSI benefits had the same prevalence of drug use as those who requalified but did not report having a payee (Swartz, Hsieh, et al. 2003). ${ }^{5}$

\section{Quality of Life}

Although many former SSI DA\&A recipients experienced difficulties in obtaining consistent employment, adequate housing, and food, the majority did not report sustained declines in these areas. In spite of the previously noted increases in residential doubling up and homelessness, most respondents were at or near baseline levels of functioning. Figure 2 shows that in other areas reflecting quality of life, such as psychological problems, legal problems, and family conflicts, $85-90$ percent of former beneficiaries reported stable or improved functioning following benefit termination (Guydish et al. 2003; Swartz and Martinovich 2003a). Moreover, the predominant pattern of stability or improvement is consistent across most of the areas assessed, regardless of SSI status and income replacement. 
Post hoc analyses reveal that former SSI DA\&A recipients most likely to report worsening problems are concentrated among those who lost and did not replace their cash benefits, as well as among those who reported the heaviest use of alcohol and other drugs at baseline. Representing 10-15 percent of the sample, these participants reported increased alcohol and drug use, family problems, and victimization over the course of the study. In a study that examined psychiatric diagnostic data collected from the Chicago sample of former DA\&A recipients, Swartz and associates (2000) find higher rates of psychiatric comorbidities among this group. Additionally, Swartz and Martinovich (2003a) find that those who lost benefits and could not replace their income were between one and a half and two times as likely as other participants to report committing a property- or drug-related crime $(\mathrm{p}<.05)$ at the 2-year follow-up. In spite of this, there were no statistically significant differences among the participants at earlier follow-up points.

\section{Discussion}

Although far fewer former DA\&A recipients requalified for SSI than predicted, the multisite study did not find widespread severe consequences for those who did not requalify and could be interviewed. Many former DA\&A beneficiaries appear to be resilient, responding to housing problems, for example, by doubling up with family or friends. In every quality of life area assessed, such as psychological functioning, drug use, and medical problems, most participants were doing at least as well at the end of the study as they were when receiving SSI. Many reported improved functioning. Still, most former SSI DA\&A beneficiaries continued to survive on society's margins, often requiring assistance from friends and relatives to meet housing and other needs. Few could afford their own apartments, and some reported transient difficulties in acquiring enough food. Participants in some sites also evidenced decreased access to medical and psychiatric services.

The absence of measurable, dramatic, and harmful changes in the lives of most surveyed former DA\&A participants means that termination of the DA\&A program could be judged successful because in the most conservative sense it did no harm. That said, such a positive assessment is qualified by a number of critically important factors. Perhaps most important is the considerable variability in participant outcomes among the study sites. In other words, it seems that the success of this policy change depends on local contexts. We know, for example, that participants in Chicago fared more poorly in terms of employment, requalification rates, and income than those in other sites. This is especially notable in San Francisco, where participants fared the best on many measures. Accordingly, a more qualified but also more accurate assessment of the effects of the DA\&A program termination would be that 
in most sites, for most participants, and on most outcomes, it did not cause undue harm. However, in some study sites, significant minorities of those who did not requalify reported low employment rates and incomes, increases in residential doubling up, and loss of health-care coverage. These are not trivial concerns.

Unfortunately, the study's design allows us to assess only the existence of contextual effects, which are manifest as differences in outcomes among the sites. We cannot determine the factors underlying these effects. We suspect that a good part of this variation in local outcomes can be explained by sturdier state and county social safety nets, as well as demographic differences. For example, Chicago had the highest proportion of young, single men. In the absence of a general assistance program in Illinois, such men had far fewer alternative income assistance options than, say, women with children, for whom TANF was an option. Further, differences in the presence and sophistication of local advocates may have significantly influenced requalification rates. In San Francisco, a high requalification rate and the existence of a general assistance program meant that relatively few former DA\&A beneficiaries were forced to rely entirely on work to survive. This limited the prevalence of outcomes, much more common in Chicago and elsewhere, that were marked by the absence of employment, income assistance, and medical benefits.

The design of the multisite study did provide for direct assessments of the extent to which those who requalified for SSI used their cash benefits to buy drugs. However, the study did not find a relationship between the prevalence of illegal drug use and requalification status or income level. Thus, while ending the DA\&A program reduced the number of illegal drug users receiving federal cash benefits, it did not reduce the number of illegal drug users. In a darker sense, this also may be a reflection of the resilience and resourcefulness of many DA\&A recipients. Former beneficiaries who actively used drugs found ways to get and pay for them, even when disability benefits stopped (Swartz, Hsieh, et al. 2003).

A related point is that ending the DA\&A program reduced but did not eliminate the number of substance users receiving disability benefits. Substance users do not sort themselves into simple categories that correspond neatly with disability-eligible conditions. As the SSA discovered while struggling to determine exactly what qualified as an alcohol- or drug-related impairment, chronic users of alcohol and other drugs often (but not always) have co-occurring psychiatric and medical conditions (Substance Abuse and Mental Health Services Administration 2002). As the urinalysis data show, the rates of illegal drug use among those who requalified for benefits are about the same as for those who did not requalify. The 1996 legislation terminated the program without affecting the prevalence of substance use. Thus, an irony of terminating the DA\&A 
program is that the illegal drug users who did requalify for disability benefits continued to receive cash benefits without having to comply with a treatment mandate or having their money managed by a representative payee.

Although the mandate for substance abuse treatment was never well enforced by the SSA, the multisite findings suggest that more rigorous enforcement of the treatment mandate increased treatment participation. This is indicated by atypically high treatment drop-out rates and low enrollment rates after the program's termination. But, we could not evaluate whether treatment participation effectively reduced substance use, because participants were not randomly assigned to treatment and because of other methodological and programmatic complexities (see Swartz, Campbell, et al. 2003). We will never learn, therefore, whether the 1994 modifications to the DA\&A program could have been effective at reducing substance use through monitored treatment.

The quasi-experimental nature of the study design and lack of random assignment to conditions (i.e., requalification for SSI) are general limitations of the study. Accordingly, we cannot claim a causal relationship between loss of SSI and higher rates of residential doubling up, for example. It may be that some third factor, such as homelessness, is associated with requalification status and is also related to residential doubling up. It could also be the case that those who did not requalify for SSI would have gone on to have higher rates of residential doubling up in the absence of the legislative change. This is unlikely, given findings from our requalifier comparison group, but it cannot be ruled out.

Another important limitation is that while the study instrument was derived mainly from validated and reliable instruments such as the ASI and the GAIN, both the validity and reliability of the instrument could be affected by combining questions from different instruments, variations in the sequencing of questions, and the addition of other questions at some sites. This could either reduce the sensitivity of the instrument or be a source of intersite variation. As a consequence, participants may have experienced more changes or larger changes than are reflected in the study's results.

Finally, other important study limitations, such as site selection, sampling frames, and sampling rates, affected the representativeness of the sample and hence the generalizability of the results. In particular, the multisite sample is not nationally representative. Because the multisite sample is not nationally representative, and because of the importance of local contexts for some outcomes (e.g., requalification rates, income, health insurance), there may be considerable variation in outcomes in unstudied jurisdictions. We cannot say, therefore, whether a more nationally representative sample would have, on the whole, poorer or better outcomes than those found for the multisite sample. 


\section{References}

Anderson, Tammy L., Caitlin Shannon, Igor Schyb, and Paul Goldstein. 2002. "Welfare Reform and Housing: Assessing the Impact to Substance Abusers." Journal of Drug Issues 32 (1): 265-96.

Campbell, Kevin, Jim Baumohl, and Sharon R. Hunt. 2003. "The Bottom Line: Employment and Barriers to Work among Former SSI DA\&A Beneficiaries." Contemporary Drug Problems 30 (1-2): 195-240.

$\rightarrow$ Cancian, Maria, Robert H. Haveman, Daniel R. Meyer, and Barbara Wolfe. 2002. "Before and After TANF: The Economic Well-Being of Women Leaving Welfare." Social Service Review 76 (4): 603-41.

Centers for Disease Control and Prevention. 2001. HIV/AIDS Surveillance Report, vol. 13, no. 2. Atlanta: U.S. Department of Health and Human Services. Retrieved from http: //www.cdc.gov/hiv/stats/hasr1302.pdf.

Choudhry, G. Hussain, and Cynthia Helba. 2003. "Rationale and Procedures for Weighting the SSI Study Data." Contemporary Drug Problems 30 (1-2): 137-46.

Cohen, William S. 1994. "Tax Dollars Aiding and Abetting Addiction: Social Security Disability and SSI Cash Benefits to Drug Addicts and Alcoholics.” Investigative Staff Report of the Minority Staff of the Senate Special Committee on Aging, 103d Cong. 2d Sess. February 7.

Davies, Paul, Howard M. Iams, and Kalman Rupp. 2000. "The Effect of Welfare Reform on SSA's Disability Programs: Design of Policy Evaluation and Early Evidence." Social Security Bulletin 63 (1): 3-11.

$\rightarrow$ Delva, Jorge, Yehuda D. Neumark, Carolyn D. M. Furr, and James C. Anthony. 2000. "Drug Use among Welfare Recipients in the United States." American Journal of Drug and Alcohol Abuse 26 (2): 335-42.

Dennis, Michael L., J. Randall Webber, William L. White, Edward Senay, L. Adams, Peter Bokos, Seth Eisenberg, James Fraser, M. Moran, Edward Ravine, Joseph Rosenfeld, and Alan Sodetz. 1996. Global Appraisal of Individual Needs (GAIN), vol. 1, Administration, Scoring and Interpretation. Bloomington, Ill.: Chestnut Health Systems.

$\rightarrow$ Goldstein, Paul J., Tammy Anderson, Igor Schyb, and James A. Swartz. 2000. "Modes of Adaptation to Termination of the SSI/SSDI Addiction Disability: Hustlers, Good Citizens, and Lost Souls." Advances in Medical Sociology 7:215-38.

Guydish, Joseph, and R. E. Claus. 2002. "Improving Publicly-Funded Drug Abuse Treatment Systems: The Target Cities Initiative.” Journal of Psychoactive Drugs 34 (1): 1-6.

Guydish, Joseph, Claudia Ponath, Alan Bostrom, Kevin Campbell, and Nancy Barron. 2003. "Effects of Losing SSI Benefits on Standard Drug and Alcohol Outcome Measures." Contemporary Drug Problems 30 (1-2): 169-94.

Harrison, Lana D. 1997. "The Validity of Self-Reported Drug Use in Survey Research: An Overview and Critique of Research Methods." Pp. 17-36 in The Validity of Self-Reported Drug Use: Improving the Accuracy of Survey Estimates, edited by Lana D. Harrison and Arthur Hughes. NIDA Research Monograph 167. Rockville, Md.: National Institute on Drug Abuse.

Hunt, Sharon R. 2000. Drug Addiction and Alcoholism as Qualifying Impairments for Social Security Disability Benefits: The History, Controversies, and Congressional Response. Ph.D. diss. Brandeis University.

Hunt, Sharon R., and Jim Baumohl. 2003a. "Drink, Drugs, and Disability: An Introduction to the Controversy." Contemporary Drug Problems 30 (1-2): 9-76.

— 2003b. "Now Invited to Testify: Former Beneficiaries Appraise the SSI Drug Addiction and Alcoholism Program." Contemporary Drug Problems 30 (1-2): 455-99.

$\rightarrow$ Jayakody, Rukmalie, Sheldon Danziger, and Harold A. Pollack. 2000. "Welfare Reform, Substance Use, and Mental Health." Journal of Health Politics, Policy, and Law 25 (4): 623-51.

Lewin Group, Inc., and Westat, Inc. 1998. "Policy Evaluation of the Effect of Legislation Prohibiting the Payment of Disability Benefits to Individuals Whose Disability Is Based on Drug Addiction and Alcoholism: Interim Report." Submitted to the Social Security Administration, Contract no. 600-96-27331. Task Order 3, Order no. 0440-97-30026. Falls Church, Va.: Lewin Group, Inc., and Westat, Inc. 
$\rightarrow$ Magura, Stephen, and Sung-Yeon Kang. 1996. "Validity of Self-Reported Drug Use in HighRisk Populations: A Meta-analytical Review.” Substance Use and Misuse 31 (9): 1131-53.

$\rightarrow$ McLellan, A. Thomas, Harvey Kushner, David Metzger, Roger Peters, Iris Smith, Grant Grissom, Helen Pettinati, and Milton Argeriou. 1992. "The Fifth Edition of the Addiction Severity Index." Journal of Substance Abuse Treatment 9 (3): 199-213.

Norris, Jean, Richard Scott, Richard Speiglman, and Rex Green. 2003. "Homelessness, Hunger and Material Hardship among Those Who Lost SSI." Contemporary Drug Problems 30 (1-2): 241-75.

Podus, Deborah, Nancy Barron, Eunice Chang, Katherine Watkins, Joseph Guydish, and M. Douglas Anglin. 2003. "Medical and Mental Health Services Utilization among Requalified and Former Drug Addiction and Alcoholism Recipients of SSI." Contemporary Drug Problems 30 (1-2): 365-90.

Podus, Deborah, Eunice Chang, Mary Lynn Brecht, James A. Swartz, and M. Douglas Anglin. 2003. "Drug Use Prevalence among Former SSI DA\&A Recipients." Contemporary Drug Problems 30 (1-2): 275-90.

$\rightarrow$ Pollack, Harold A., Sheldon Danziger, Kristin Seefeldt, and Rukmalie Jayakody. 2002. "Substance Use among Welfare Recipients: Trends and Policy Responses." Social Service Review 76 (2): 256-74.

$\rightarrow$ Satel, Sally L. 1995. "When Disability Benefits Make Patients Sicker." New England Journal of Medicine 333 (12): 794-96.

Satel, Sally L., and William M. Glazer. 1993. "Supporting Addiction with Public Funds." Hospital and Community Psychiatry 44 (10): 913.

Scott, Richard, and Jim Baumohl. 2003. "Decisions to Appeal, Decisions to Approve: Requalification for SSI by Former DA\&A Beneficiaries." Contemporary Drug Problems 30 (1-2): 147-68.

$\rightarrow$ Shaner, Andrew, Thad A. Eckman, Lisa J. Roberts, Jeffery N. Wilkins, Douglas E. Tucker, John W. Tsuang, and Jim Mintz. 1995. "Disability Income, Cocaine Use, and Repeated Hospitalization among Schizophrenic Cocaine Abusers-a Government-Sponsored Revolving Door?” New England Journal of Medicine 333 (12): 777-83.

Solomon-Fears, Carmen D. 1997. Drug Addicts and Alcoholics Are No Longer Eligible for Supplemental Security Income (SSI). Report 97-321. Congressional Research Service, Washington, D.C.

Speiglman, Richard, Jean Norris, Shanthi Kappagoda, Rex G. Green, and Zoran Martinovich. 2003. "SSI Receipt and Alcohol and Other Drug Use among Former SSI DA\&A Beneficiaries." Contemporary Drug Problems 30 (1-2): 291-334.

Substance Abuse and Mental Health Services Administration (SAMHSA). 2002. Report to Congress on the Prevention and Treatment of Co-occurring Substance Abuse Disorders and Mental Disorders. Rockville, Md.: SAMHSA. Retrieved at: http://www.samhsa.gov/ reports/congress2002/CoOccurringRpt.pdf.

Swartz, James A., Kevin Campbell, Jim Baumohl, and Peggy Tonkin. 2003. "Drug Treatment Participation and Retention Rates among Former Recipients of Supplemental Security Income for Drug Addiction and Alcoholism." Contemporary Drug Problems 30 (1-2): $335-64$.

$\rightarrow$ Swartz, James A., Chang-ming Hsieh, and Jim Baumohl. 2003. "Disability Payments, Drug Use, and Representative Payees: An Analysis of the Relationships." Addiction 98 (7): $965-75$.

Swartz, James A., and Arthur J. Lurigio. In press. "Severe Mental Illness and Substance Use Disorders among Former Recipients of Supplemental Security Income (SSI) for Drug Addiction and Alcoholism." Journal of Offender Rehabilitation.

$\rightarrow$ Swartz, James A., Arthur J. Lurigio, and Paul Goldstein. 2000. "Severe Mental Illness and Substance Use Disorders among Former Supplemental Security Income (SSI) Beneficiaries for Drug Addiction and Alcoholism." Archives of General Psychiatry 57 (7): $701-7$.

Swartz, James A., and Zoran Martinovich. 2003a. "An Analysis of the Criminogenic Effects of Terminating the Supplemental Security Income Impairment Category for Drug Addiction and Alcoholism." Contemporary Drug Problems 30 (1-2): 391-424.

— . 2003b. "General Course and Correlates of Improvement and Decline Following Termination of the Supplemental Security Income Impairment Category for Drug Addiction and Alcoholism." Contemporary Drug Problems 30 (1-2): 425-54.

Swartz, James A., Peggy Tonkin, and Jim Baumohl. 2003. "The Methodology of the Multi- 
Site Study of the Termination of Supplemental Security Income Benefits for Drug Addicts and Alcoholics." Contemporary Drug Problems 30 (1-2): 77-122.

$\rightarrow$ Watkins, Katherine E., Deborah Podus, and Emilia Lombardi. 2001. "The Health and Mental Health of Disabled Drug Abusers." Journal of Behavioral Health Services and Research 28 (2): 205-11.

Wehler, Cheryl A., Richard Scott, and Jennifer J. Anderson. 1996. "Development and Testing Process of the Community Childhood Hunger Identification Project Scaled Hunger Measure and Its Application for a General Population Survey." Appendix A in Conference on Food Security Measurement and Research: Papers and Proceedings, January 1994, Technical Appendix A. Alexandria, Va.: U.S. Department of Agriculture, Food and Consumer Service.

Wittenburg, David, David Stapleton, Adam Tucker, and Rick Harwood. 2003. "An Assessment of the Representativeness of the SSI DA\&A Study Panels." Contemporary Drug Problems 30 (1-2): 123-36.

\section{Notes}

We gratefully acknowledge support for this research from the Center for Substance Abuse Treatment, Rockville, Maryland, under grant 5-U95-TI00664-05 and from the Robert Wood Johnson Foundation's Substance Abuse Policy Research Program under grant 031602. We also extend our thanks to Melody Heaps and Dan Luchins for their reviews and comments on earlier drafts of this article.

1. The full DA\&A caseload at the time of program termination was 209,374 cases. These comprised those cases eligible only for SSI ( 57 percent), those concurrently eligible for SSI and Social Security Disability Insurance (DI; 22 percent), and those eligible only for Disability Insurance (21 percent; Davies, Iams, and Rupp 2000). Of those who collected SSI, 51.4 percent were categorized by the SSA as alcoholics only, 17.7 percent as drug addicts only, and 30.8 percent as both alcoholics and drug addicts.

2. The SSA runs two programs for the disabled: Social Security Disability Insurance and Supplemental Security Income. The DI program provides disability benefits based on average lifetime earnings to individuals who have worked at least 10 of the past 20 quarters, and SSI is for disabled individuals who do not qualify for DI benefits because of a poorer work history and who have less than $\$ 2,000$ in assets (for individuals). Both SSI and DI have DA\&A programs. Some people qualify for both SSI and DI benefits (i.e., they are concurrent beneficiaries) because their DI benefits are small. Both the SSI and DI DA\&A programs required recipients to participate in drug treatment and to have a representative payee, but these requirements were added to the DI program only in 1994 (see Hunt and Baumohl $2003 a$ for more information on the SSI and DI DA\&A programs). The study in question here does not include DI or concurrent beneficiaries.

3. The San Francisco site had two separate cohorts. One cohort comprised 153 former DA\&A recipients randomly selected from a list obtained from the RMA in California. This cohort is included in all the multisite analyses summarized in this article. A second San Francisco cohort of 66 former DA\&A recipients was nonrandomly selected from among treatment participants in the Target Cities project. Because of its uniqueness in terms of selection criteria, its small size, and its geographical overlap with the other San Francisco cohort, data from the Target Cities sample in San Francisco were excluded from the analytic database and analyses. Instead, the Target Cities sample served primarily to validate the Addiction Severity Index (ASI) questions embedded in the multisite study questionnaire (see Swartz, Tonkin, et al. 2003).

4. The clearance rate for alcohol is so rapid that an accurate estimate of alcohol consumption for the past two or three days, the detection window for most other drugs, is not possible with current technology.

5 . While having a representative payee was a requirement of the DA\&A program, it is discretionary for other SSI beneficiaries. SSI recipients with psychiatric and other medical disabilities can be assigned a representative payee if, in the judgment of the SSA fieldworker, they need one because they do not demonstrate an ability to manage their own finances (e.g. because of a severe psychiatric disorder that affects their judgment; see Hunt and Baumohl 2003a). 